\title{
Deformidades ungulares em vacas Holandesas
}

Bruno Alcantara Sampaio Pinto ${ }^{[a]}$, Muriel Magda Lustosa Pimente ${ }^{[b]}$, Regina Valéria da Cunha Dias ${ }^{\left[c^{0}\right.}$, Tatiana Leite Barbosa Araújo dos Santos ${ }^{[[]}$, Rivaldo Bruno Medeiros de Lucena ${ }^{[c]}$, Ilanna Vanessa Pristo de Medeiros Oliveira ${ }^{[c]}$, Felipe Venceslau Câmara $^{[\mathrm{d}]}$

\author{
[a] Médico veterinário \\ [b] Centro Universitário Cesmac (CESMAC), Maceió, AL, Brasil \\ [c] Universidade Federal Rural do Semi-Árido (UFERSA), Mossoró, RN, Brasil

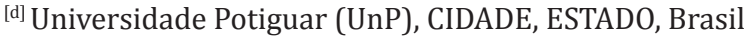

*Autor correspondente

e-mail: regina@ufersa.edu.br

\section{Resumo}

Apesar de animais com problemas de cascos serem capazes de produzir, seu desempenho é baixo. Aproximadamente $90 \%$ das alterações do sistema locomotor dos bovinos ocorrem nos cascos. Esse estudo foi realizado com o objetivo de avaliar as lesões podais que prejudicam a produtividade das vacas Holandesas. Utilizou-se 17 vacas da raça Holandesa da Universidade Federal Rural do Semi-Árido, criadas sob sistema de criação semi-intensivo. Os animais passaram por contenção química com uso de Xilazina 2\%, na dose de 0,25mg.kg-1 ${ }^{-1}$ IV, além de contenção física com a técnica de Rueff. Os cascos foram limpos com água corrente e escova. Foi avaliada a presença de deformidades ungulares: cascos achinelados, pinças em forma de tesoura e hipercrescimento. Os dados qualitativos foram descritos através de porcentagem. Além disso, foi utilizado o teste Qui-quadrado para examinar a associação entre os dados e a ocorrência de deformidades ungulares. Os valores significativos no teste do Qui-quadrado foram submetidos à regressão logística binária e estimadas as razões de chances. Foram consideradas as razões de chances $>1$ como fatores de risco ou predisponentes, e resultados $<1$ como variáveis preventivas ou protetores. Foi utilizado o Two Way ANOVA, seguido de regressão logística binária, para comparar a ocorrência de deformidade ungular "unhas em tesoura". Todas as análises foram realizadas considerando nível de significância de 5\% e intervalo de confiança (IC) de 95\%. $88 \%$ das vacas avaliadas $(\mathrm{n}=15)$ apresentaram deformidade do casco em forma de tesoura. Desses animais, $70,59 \%$ das deformidades foram observadas nos membros torácicos, com total de 48 dígitos, e 20,59\% nos membros pélvicos, com total de 14 dígitos, demostrando assim, 9,25 mais chances de desenvolver essa enfermidade nos membros torácicos do que nos pélvicos $(\mathrm{P}<0,05)$. Com isso, pode-se observar que 
a maior incidência das deformidades de cascos em vacas foi em forma de tesoura. Isso pode ter ocorrido devido ao piso e/ou manejo, pois esses são fatores que contribuem para o crescimento excessivo dos cascos das vacas, além do excesso de concentrado na dieta que pode causar doenças digitais crônicas, levando a uma posterior deformidade em forma de tesoura. Foi observado hipercrescimento de dígito em 2,94\% dos membros torácicos com total de 2 dígitos, e em 5,88\% dos membros pélvicos, representando quatro dígitos. 0 hipercrescimento é uma deformidade ungular associada à ocorrência prévia de laminite, todavia, como neste estudo não foi diagnosticada essa enfermidade, acredita-se que esse crescimento excessivo tenha ocorrido devido à falta de desgaste natural do casco. Pode-se especular que ambiente, manejo, nutrição, genética e instalações podem ter influência direta no aparecimento de alterações de medidas morfológicas e de deformidades ungulares de vacas e novilhas nas condições relatadas no presente estudo. 